\title{
Anticipated efficiencies, real costs: Medicaid managed care organizations and the pharmacy benefit
}

\author{
Liam Bendicksen and Aaron S Kesselheim, MD, JD, MPH
}

\section{SUMMARY}

The Affordable Care Act led an additional 15 states to begin contracting with comprehensive, risk-based managed care organizations (MCOs) to administer pharmacy benefits for Medicaid beneficiaries between 2010 and 2017. Reasons for this shift included concerns about administering complex benefits for an influx of new beneficiaries, assumptions about the cost-saving potential of privately run managed care, and a desire for budget predictability. As drug prices increased during the past decade, the way that state pharmacy benefits were administered via
MCOs affected the ability of states to meet the needs of their Medicaid beneficiaries. Here, we review the advantages and limitations of 2 strategies that give states more centralized control over management of the pharmacy benefit: excluding the pharmacy benefit from MCO contracts and aligning preferred drug lists across beneficiary types. We propose that centralizing utilization management tools, aligning incentives for managed care payers with the needs of patients and Medicaid programs, and the ability to implement formulary exclusions may enable states to achieve savings and better meet the needs of beneficiaries.
Medicaid enrollment has risen by approximately 24 million people nationwide since the Patient Protection and Affordable Care Act (ACA) authorized states to expand the program beginning in 2014. ${ }^{1}$ Roughly 10 million of these patients enrolled in Medicaid after February 2020, coverage gains that were likely precipitated by the economic pressures of the COVID-19 pandemic. As more people enrolled in Medicaid following the enactment of the ACA, states increasingly relied on Medicaid managed care organizations (MCOs) to administer benefits for their enrollees. After the ACA's enactment, states enrolled 20 million additional new and existing Medicaid enrollees in MCOs between 2013 and $2018 .^{2}$ As of July 1, 2019, only 11 state Medicaid programs did not contract with comprehensive, risk-based MCOs to administer at least some services for their beneficiaries. ${ }^{3}$ Although Medicaid nonexpansion states make up a disproportionate share of these programs that do not contract with MCOs in any capacity, several nonexpansion states, including Texas and Florida, increased their use of such contracts after the ACA's enactment.

Over the past decade, prescription drug costs have become a major source of spending for Medicaid programs due to heightened enrollment, premium launch prices of new prescription drugs, and a lack of prescription drug price negotiation or price controls at the federal level. ${ }^{4}$ Although the federal government

\section{Author affiliations}

Liam Bendicksen and Aaron S Kesselheim, MD, JD, MPH, Program On Regulation, Therapeutics, And Law (PORTAL), Division of Pharmacoepidemiology and Pharmacoeconomics, Department of Medicine, Brigham and Women's Hospital and Harvard Medical School, Boston, MA.

\section{AUTHOR CORRESPONDENCE:}

Aaron Kesselheim, 617.289.0930;

akesselheim@bwh.harvard.edu

J Manag Care Spec Pharm 2022;28(3):354-61

Copyright $\odot 2022$, Academy of Managed Care Pharmacy. All rights reserved.

foots most of the bill for Medicaid drug costs, states still spend millions on prescription drugs in the program every year, which they must balance against their ability to deliver other necessary medical services through Medicaid. ${ }^{5,6}$ To help mitigate this strain, the ACA made sweeping changes to how Medicaid pays for drugs, such as increasing statutory rebates for brand-name drugs and generics under the Medicaid Drug Rebate Program and extending those rebates to drugs prescribed for beneficiaries in Medicaid MCOs. ${ }^{7,8}$ The share of states with comprehensive, risk-based Medicaid MCOs that 
included the pharmacy benefit in managed care contracts also increased dramatically, from 20 states in 2010 to 35 states in 2017. ${ }^{9}$

Despite the extensive use of MCOs to administer the Medicaid pharmacy benefit, few peer-reviewed studies have evaluated the effects of state programs contracting with MCOs to administer this benefit. Also, much of the literature that does exist on the effects of these policies is outside of the medical literature and is funded by organizations with financial interests at stake.10,11

In this article, we first review why states initially relied on Medicaid MCOs to administer the pharmacy benefit after the ACA's Medicaid provisions went into effect. We then examine why, as a result of mismatched incentives that have generated wasteful spending, some states have recently eliminated or limited their pharmacy benefit administration contracts with Medicaid MCOs. We evaluate the potential benefits and limitations of 2 options for reducing the role of Medicaid MCOs in administering the pharmacy benefit: aligning preferred drug lists (PDLs) across beneficiary types and either incentivizing MCOs to minimize state program costs or carving the pharmacy benefit out of managed care contracts. We conclude by outlining several policy alternatives that could help states control Medicaid drug spending without compromising patient access to needed medicines.

\section{Supplemental Rebates and PDLs: The Next-Best Alternative to Formulary Exclusions}

Under federal law, state Medicaid programs that offer outpatient drug coverage to beneficiaries must cover almost every prescription drug approved by the US Food and Drug Administration (FDA). ${ }^{8}$ Faced with high-priced brandname drugs and growing numbers of enrollees, program administrators must therefore turn to methods other than formulary exclusions to limit spending. Two of the most prevalent tools in state arsenals for curbing drug costs are supplemental rebate agreements and PDLs.

In addition to the statutorily defined rebates for prescription drugs that manufacturers must pay to states and the federal government under Section 1927 of the Social Security Act, state Medicaid programs and contracting MCOs may also negotiate with manufacturers for supplemental rebates. In exchange for these supplemental rebates, which lower the net cost of drugs, states or Medicaid MCOs place manufacturer products in a preferred position on their PDLs. ${ }^{?}$
PDLs can facilitate several different strategies for driving patients towards using drugs with lower post-rebate costs, such as prior authorization requirements and step therapy rules. In most states, clinicians must seek permission, known as prior authorization, before Medicaid programs or subcontracting MCOs and pharmacy benefit managers (PBMs) will cover nonpreferred drugs. When there are multiple pharmacological treatments for a given medical condition, states often require Medicaid enrollees to start on a lower-cost drug for that condition and only allow the substitution of a higher-cost alternative if such a change is deemed medically necessary ${ }^{12}$; this process is known as step therapy. According to a 2019 Kaiser Family Foundation survey, 41 states (all except Arkansas, Hawaii, Louisiana, Minnesota, Nevada, New Mexico, Pennsylvania, Texas, and Utah) have instituted a step therapy policy for at least 1 indication. ${ }^{3}$ However, these policies are not always costeffective. For example, a 2008 study found that Georgia's implementation of a step therapy policy for certain antipsychotic medications was associated with roughly $\$ 20$ in savings per Medicaid member with schizophrenia per month, yet the policy was also associated with approximately \$32 in increased outpatient spending per member with schizophrenia per month..$^{13}$ Avoiding these strategies and receiving favorable Medicaid PDL placement, much like favorable commercial formulary placement, drives up prescribing, so states can therefore leverage it to extract supplemental rebates from manufacturers. Forty-five states and the District of Columbia had a fee-for-service PDL in place as of July 2019. ${ }^{14}$

Negotiating supplemental rebate agreements in conjunction with other Medicaid programs helps states to maximize this leverage and secure better discounts. As of December 2020, 31 states had formed drug purchasing alliances to do just that, ${ }^{15,16}$ and 47 states and the District of Columbia had reached at least 1 agreement with manufacturers to secure supplemental rebates, whether independently or as part of a multistate purchasing alliance, as of the same date.

\section{Responding to the ACA: A Move Towards Managed Care}

Between the enactment of the ACA and the end of fiscal year 2017, an additional 15 state Medicaid programs began contracting with MCOs to manage the pharmacy benefit. ${ }^{9}$ States carved pharmacy benefits into risk-based contracts with MCOs in response to increased enrollment, strained budgets, uncertainty about the ability of state programs to administer pharmacy benefits for an influx of new beneficiaries, and the ACA's provision that states could collect 
statutory rebates for drugs prescribed to $\mathrm{MCO}$-covered beneficiaries. As these private payers began administering pharmacy benefits for millions of newly enrolled Medicaid beneficiaries, states generally allowed MCOs to oversee their own PDLs and utilization management tools. ${ }^{9,17}$

\section{The Perils of Mismatched Incentives: Reconsidering the Utility of Medicaid MCOs in Administering the Pharmacy Benefit}

As more high-priced new therapies have received FDA approval in recent years, a growing number of states have reconsidered their use of managed care contracts to administer the Medicaid pharmacy benefit. This shift reflects a possible conclusion by state Medicaid officials that MCOs have not consistently achieved meaningful cost savings. For example, the California Department of Health Care Services estimated that administering pharmacy benefits for all Medicaid beneficiaries in the state under a fee-forservice model would "result in ongoing annual savings of \$859 million total funds." ${ }^{18}$ State officials cited increased supplemental rebates and reduced administrative costs as mechanisms by which such a shift could achieve savings. ${ }^{19}$

One explanation for this perception of inefficiency is that Medicaid MCOs do not collect statutory or inflationary rebates under the Medicaid Drug Rebate Program for outpatient drugs dispensed to their beneficiaries. ${ }^{20}$ This creates an incentive for these organizations to direct patients towards drugs with lower list prices rather than drugs with lower net post-rebate prices. Faced with a choice between filling a script for a new drug that costs $\$ 10$ or an older drug for the same indication that has a list price of $\$ 20$ but a post-rebate cost of $\$ 8$, MCOs that maintain an independent PDL have an incentive to steer patients towards the newer drug, despite its higher net cost to government payers.

Medicaid MCOs that are at risk for administering pharmacy benefits for their beneficiaries may also collect their own additional rebates from manufacturers, which can further exacerbate this mismatch in incentives. As of July 2019, Medicaid programs in approximately 35 states and the District of Columbia contracted with MCOs in any capacity to help administer the pharmacy benefit. ${ }^{3}$

Programs that contract with Medicaid MCOs to administer the pharmacy benefit must account for the profit-seeking practices of PBMs that function as intermediaries facilitating the flow of money from Medicaid
MCOs to pharmacies..$^{21,22}$ One way PBMs make money is by reimbursing pharmacies less than what Medicaid MCOs allot to them for a given prescription claim and pocketing the difference, a practice known as "spread pricing." ${ }^{23}$ This business strategy adds no value to patients or the health system but generates millions of dollars in profits for PBMs. ${ }^{24}$ Spread pricing also financially squeezes pharmacies, raising the risk that vulnerable businesses such as rural independent pharmacies will close their doors to patients who need their services..$^{25,26}$

Although spread pricing occurred before Medicaid expansion under the ACA, public awareness of this practice has only recently fueled a growing sense among lawmakers that contracting with MCOs may not be the best way to operate the Medicaid pharmacy benefit. ${ }^{27}$ In 1 reaction to concerns about spread pricing, the Louisiana state legislature in 2019 simultaneously outlawed the practice and authorized the state's Medicaid program to carve pharmacy benefits out of MCO contracts. ${ }^{28}$

As the financial burden of spread pricing, rebate collection issues that motivate MCOs to dispense drugs with higher net costs to states, and other practices stemming from mismatched incentives have worsened, a growing number of states have discontinued their use of Medicaid MCOs to administer the pharmacy benefit or have sought to realign $\mathrm{MCO}$ incentives by establishing a uniform PDL for all beneficiaries. ${ }^{3}$

\section{Pharmacy Benefit Carve-Outs}

We first review the potential benefits of carving the pharmacy benefit out of Medicaid MCO contracts. We then evaluate potential drawbacks and note any circumstances or factors that may mitigate these downsides.

To date, approximately 6 states (California, Missouri, North Dakota, Tennessee, West Virginia, and Wisconsin) have carved the pharmacy benefit out of Medicaid managed care contracts. ${ }^{3,18,29}$ New York originally planned to execute a carve out in April 2021, but the state's legislature postponed the transition until April 1, 2023..$^{30}$ The New York Department of Health website indicates that when the carve out is put into practice, it will "centralize and leverage negotiation power," establish "a single drug formulary with standardized utilization management protocols," "address the growth of the $340 \mathrm{~B}$ program and associated reductions," and offer the state "full visibility into prescription drug costs." States using a carved-out Medicaid pharmacy benefit model generally contract with PBMs to adjudicate claims and administer utilization management tools, although some states perform these functions in-house. ${ }^{3}$ 


\section{POTENTIAL BENEFITS}

Carving pharmacy benefits out of risk-sharing contracts with Medicaid MCOs, even if only for select drug classes, may offer states a variety of benefits. For instance, eliminating managed care intermediaries allows Medicaid officials to implement program modifications more universally. When new high-priced drugs receive FDA approval, a centralized decision-making structure equips state regulators to negotiate steeper supplemental rebates and institute programwide utilization management models. ${ }^{9}$

By maximizing the number of covered lives that states may leverage in negotiations for supplemental rebates, carve-outs can also help states achieve higher discounts and better deals for costly therapies. ${ }^{7}$ For instance, while New Hampshire's Medicaid program generally carves the pharmacy benefit into MCO contracts, the state secured an additional \$3.5 million in supplemental rebate revenues in 2018 after carving out 2 individual high-cost drugs, as well as all hemophilia therapies and hepatitis $\mathrm{C}$ treatments. ${ }^{31}$ This limited evidence suggests that carve-outs have already helped states secure better discounts on expensive drugs, although the details of supplemental rebate agreements are generally confidential. Supplemental rebates have also been used by Medicaid programs in conjunction with carve-outs as a vehicle to execute alternative payment models for high-cost prescription drugs. ${ }^{4}$ For example, outcomesbased contracts require that manufacturers pay states supplemental rebates if their drugs fail to make an impact on certain agreed-upon health outcomes.

Carving the pharmacy benefit out of managed care contracts may improve access to medicines for some Medicaid beneficiaries. While Medicaid fee-for-service pharmacy benefit models rarely implement restrictive pharmacy networks, selective contracting and narrow pharmacy networks are a core part of cost-cutting strategies used by Medicaid MCOs., ${ }^{3,17}$ Having fewer pharmacies "in network" means that Medicaid MCOs will cover prescriptions at fewer pharmacies than fee-for-service programs. If eliminating managed care intermediaries increases the number of in-network pharmacies for patients in a given Medicaid program, access may improve, particularly for beneficiaries who reside in geographic areas with a shortage of community pharmacies. ${ }^{32}$ This is because rural Medicaid MCO beneficiaries may have to travel farther than feefor-service beneficiaries to reach a pharmacy that carries their medicines and is in network, potentially threatening medication adherence. Carve-outs also can help simplify the establishment of uniform PDLs, which standardize outpatient drug benefits for all beneficiaries.

\section{POTENTIAL LIMITATIONS}

Carving pharmacy benefits out of Medicaid managed care contracts may increase drug spending. Using pre-rebate pricing data, 1 study estimated that Medicaid outpatient drug spending would fall by $22 \%$ if MCOs administered the pharmacy benefit for every beneficiary nationwide. ${ }^{17}$ The authors attributed roughly two-thirds of this reduction in spending to better generic penetration in MCOs and the remaining one-third to more restrictive pharmacy networks leading to lower point-of-sale prices. However, this analysis did not factor in some confidential rebates, so the magnitude of increases in spending that carve-outs may produce are unclear; the effects on spending of carving out specific classes of drugs are similarly uncertain.

Carve-outs also incentivize MCOs to steer Medicaid beneficiaries towards drugs that could help prevent future, nonpharmacy expenditures, since these savings benefit contracting payers at no cost to their bottom line. Future research should explore the fiscal implications of this dynamic for Medicaid programs, since MCOs in carve-out states have a substantial financial interest in encouraging beneficiaries to use effective prescription drugs without regard for cost.

When states choose to carve out pharmacy benefits, they must bear or redelegate the administrative burden of program management that had previously fallen to MCOs. Outsourcing responsibility for the full range of tasks that pharmacy benefit administration involves, from paying claims to managing prior authorization requests, is convenient. States do not necessarily need to administer claims in-house if they choose to remove the pharmacy benefit from MCO contracts. PBMs currently perform some or all administrative tasks related to fee-for-service pharmacy delivery for the overwhelming majority of state Medicaid programs,$^{3}$ and they could easily administer the pharmacy benefit for all Medicaid beneficiaries in states interested in moving to a carved-out model.

Since Medicaid managed care plans generally report substantially higher administrative overhead than publicly administered Medicaid, a carved-out structure could potentially generate administrative savings. ${ }^{33}$ In response to this and other arguments, some MCOs have argued that pharmacy benefit carve-outs impede their ability to provide holistic care, since a poorly executed carve-out could render real-time pharmacy data unavailable to clinicians. ${ }^{34}$ This concern could be mitigated if carve-out states follow the lead of Missouri and other states in developing infrastructure for MCOs, pharmacies, and prescribers to access a shared portal of real-time utilization and claims data. ${ }^{8}$ 


\section{Uniform PDLs}

Establishing a uniform PDL for fee-for-service and MCO Medicaid beneficiaries, whether for all prescription drugs or specific classes, is another strategy that state Medicaid programs have explored in recent years. States can execute this policy regardless of whether pharmacy benefits are carved into or out of risk-sharing managed care contracts. One survey of state Medicaid programs found that 9 states (Arkansas, Delaware, Iowa, Kansas, Louisiana, Minnesota, Mississippi, North Dakota, and Texas) had implemented a uniform PDL for all drug classes, and an additional 7 (Arizona, Florida, Massachusetts, Nebraska, South Carolina, Virginia, and Washington) had a uniform PDL in place for at least some drug classes as of July 2019.,14 We first detail the potential benefits for state Medicaid programs that establish a uniform PDL and then assess the limitations of this structure.

\section{POTENTIAL BENEFITS}

By virtue of eliminating variations in prior authorization rules, maintaining a single statewide PDL for all Medicaid beneficiaries would make it easier for providers and patients to understand and navigate PDLs. ${ }^{35}$ In addition, establishing more straightforward rules for prior authorizations may mean that providers will spend less time navigating frustrating procedures. ${ }^{36}$

Uniform PDLs eliminate the need for each Medicaid MCO to develop and manage its own PDL, helping to improve administrative efficiency. Given the volatility of Medicaid eligibility and the resulting movement of beneficiaries in and out of state programs, a uniform PDL can also help minimize adherence-threatening disruptions in access that occur when beneficiaries change managed care plans or reenroll in Medicaid, such as the high-risk period when people reenter the broader community after being incarcerated. ${ }^{37,38}$ Uniform PDLs generally allow for easier coordination of programwide public health initiatives for all beneficiaries. ${ }^{9}$

\section{POTENTIAL LIMITATIONS}

Uniform PDL structure has a few limitations. The implementation of a uniform PDL may disincentivize MCOs from developing and carrying out population health initiatives and outcomes-based pricing strategies by removing private payers' individualized leverage and ability to carry out these programs. Limited evidence also suggests that uniform PDLs may increase drug costs. A 2018 observational study comparing 2 Medicaid MCOs in different states, one with a single statewide PDL and the other without, found that beneficiaries in the former had decreased utilization but increased expenditures. ${ }^{39}$

Creating a uniform PDL may lead to a one-time disruption in patient access to medications that were previously preferred drugs but are no longer preferred under the new PDL. Additionally, the establishment of a uniform PDL does not guarantee programwide alignment in clinical coverage criteria and guidelines. For example, despite operating a single uniform PDL, the Texas Medicaid program allows partnering MCOs to set their own unique clinical coverage criteria, which has caused variations in access and confusion among providers. ${ }^{40}$ As of the end of fiscal year 2019, 31 of the 35 states that generally carved the pharmacy benefit into comprehensive, risk-based MCO contracts required those MCOs to implement uniform, state-mandated clinical coverage criteria. ${ }^{41}$

\section{A Roadmap for Reform}

\section{CENTRALIZING UTILIZATION MANAGEMENT TO ACHIEVE SAVINGS}

Even if states decide not to establish a uniform PDL for all drug classes, officials should consider implementing a uniform PDL on a class-by-class or drug-by-drug basis for new therapies. A small percentage of prescription drugs account for a disproportionate and growing share of Medicaid pharmacy expenditures. ${ }^{42}$ As high-cost products that could be useful for broad Medicaid populations continue to come down the pipeline, executing a uniform PDL for specific expensive drug classes would offer states leverage and centralized control to manage utilization and lower costs. The tangible benefits of this approach are readily observable in the case of Missouri's Medicaid program: In 2014, a uniform PDL and carved-out pharmacy benefit structure allowed the state to respond rapidly to the market entry of new and expensive hepatitis $C$ drugs..$^{9,43}$ After negotiating for supplemental rebates from 1 manufacturer with the assistance of a 25-state purchasing pool, Missouri placed that company's product in a preferred position and relegated competing therapies to nonpreferred status, helping to save the state money while ensuring consistent access for beneficiaries. ${ }^{44,45}$

\section{REALIGNING INCENTIVES FOR MCOS TO MAXIMIZE SAVINGS}

Policymakers should also consider more closely aligning the bottom line of Medicaid MCOs with savings for states and the federal government. MCOs can be a powerful force in controlling costs without sacrificing the quality of care, but that ability to curb spending is only possible if MCOs 
share in the savings they help generate. ${ }^{17}$ To move towards this goal of aligning financial incentives for MCOs with states' goals and interests, policymakers could allow state programs to share a percentage of supplemental rebate revenues with MCOs. One way to accomplish this outcome would be to incorporate a revenue-sharing agreement into state contracts with Medicaid MCOs.

\section{FORMULARY EXCLUSIONS}

One particularly intractable factor constraining the ability of state Medicaid programs to curb rising prescription drug expenditures is that the Medicaid Drug Rebate Program (MDRP) requires that Medicaid pharmacy benefits include almost every FDA-approved drug. While the MDRP has generated hundreds of billions of dollars for Medicaid since the rebate program's establishment in 1990, this requirement severely limits the latitude of officials to respond to an ever more expensive array of FDA-approved therapies. ${ }^{8}$ PDLs and utilization management models are a poor substitute for the closed formulary designs that commercial payers employ. ${ }^{46}$ Researchers have argued that a closed formulary, meaning the exclusion of some therapies from coverage, could be ethically applied to Medicaid under certain circumstances. ${ }^{47}$ To manage escalating costs in the current pricing landscape, federal policymakers should consider removing the requirement that state programs maintain an open formulary.

Although Medicaid programs may not implement formulary exclusions, some states have found that selective contracting via alternative payment models can confer similar benefits. ${ }^{8}$ The Centers for Medicare \& Medicaid Services has recently allowed some programs to sign novel contracts with manufacturers of certain highcost drugs. Much like commercial formulary exclusions, these contracts allow states to offer manufacturers exclusive or near-exclusive access to their beneficiary populations in exchange for deep discounts. In Louisiana and Washington State, for example, Medicaid programs have signed selective, subscription-model contracts with manufacturers of hepatitis $\mathrm{C}$ therapies, exchanging a fixed annual payment for an unlimited supply of antivirals at no marginal cost to the state. ${ }^{48}$ Scholars have argued that these novel subscription-based payment models did not produce cost savings as a result of experimental pricing arrangements ${ }^{49}$; instead, the benefits of these arrangements may have derived from the 2 states' selective contracts with single manufacturers.

Congress should revisit the MDRP's requirement that states cover nearly all FDA-approved drugs. PDLs, which effectively function as a substitute for formulary tiering and exclusions at the moment, are a far-from-perfect substitute for closed formularies. If policymakers take care to safeguard access by beneficiaries, such as by ensuring coverage of at least 1 drug per therapeutic class and making coverage decisions based on therapeutic value, closed formularies could ethically reduce spending on low-value drugs, although the magnitude of such savings remains unclear. ${ }^{50}$

\section{Conclusions}

The Affordable Care Act drove many states to outsource the administration of Medicaid pharmacy benefits to MCOs. State Medicaid programs largely carried out this policy overhaul in the absence of substantial real-world evidence. A decade later, many states have reversed course, establishing more uniform PDLs and carving pharmacy benefits out of Medicaid managed care contracts.
Although the effects of these changes on health care costs and access will be state-specific, states that currently contract with MCOs to administer the pharmacy benefit should consider taking action to align incentives for contracting MCOs with the needs of Medicaid patients and program budgets. Although substantial heterogeneity in state program objectives and administrative capacities makes a one-size-fits-all approach untenable, policymakers should strongly consider retaking some control over the administration of Medicaid pharmacy benefits, such as by establishing a single PDL or carving pharmacy benefits out of Medicaid managed care contracts.

\section{DISCLOSURES}

No funding supported the writing of this Viewpoints article. Kesselheim is supported by grants from Arnold Ventures. Bendicksen has nothing to disclose.

\section{REFERENCES}

1. Medicaid and CHIP Payment and Access Commission. Full-benefit Medicaid and CHIP enrollment, selected months in 2013-2020. December 2020. Accessed August 3, 2021. https://www.macpac. gov/wp-content/uploads/2015/11/ EXHIBIT-11.-Full-Benefit-Medicaid-andCHIP-Enrollment-Selected-Months-in2013\%E2\%80\%932021.pdf

\section{Kaiser Family Foundation. Total} Medicaid MCO enrollment. 2020. Accessed August 3, 2021. https://www.kff. org/other/state-indicator/total-medicaid-mco-enrollment $/$ ?activeTab $=$ graph\&c urrentTimeframe $=0 \&$ start Timeframe $=5 \&$ sortModel=\%7B\%22colId\%22:\%22Location \%22,\%22sort\%22:\%22asc\%22\%7D 
3. Gifford K, Winter A, Wiant L, Dolan R, Tian M, Garfield R. How state Medicaid programs are managing prescription drug costs results from a state Medicaid pharmacy survey for state fiscal years 2019 and 2020. Kaiser Family Foundation. April 2020. Accessed August 3, 2021. https://files.kff.org/attachment/ How-State-Medicaid-Programs-areManaging-Prescription-Drug-Costs.pdf

4. Sachs R. Prescription drug policy: the year in review, and the year ahead. Health Affairs Blog. January 7, 2021. Accessed August 3, 2021. https://www.healthaffairs. org/do/10.1377/hblog20210106.852741/full/

5. Rudowitz R, Garfield R, Hinton E. 10 things to know about Medicaid: setting the facts straight. Kaiser Family Foundation. March 6, 2019. Accessed August 3, 2021. https://www.kff.org/medicaid/ issue-brief/10-things-to-know-aboutmedicaid-setting-the-facts-straight/

6. Medicaid and CHIP Payment and Access Commission. MACStats: Medicaid and CHIP data book. December 2020. Accessed August 3, 2021. https:// www.macpac.gov/wp-content/ uploads/2020/12/MACStats-Medicaidand-CHIP-Data-Book-December-2020.pdf

7. Dolan R. Understanding the Medicaid prescription drug rebate program. Kaiser Family Foundation. November 12, 2019. Accessed August 3, 2021. https:// www.kff.org/medicaid/issue-brief/ understanding-the-medicaid-prescription-drug-rebate-program/

8. Centers for Medicare \& Medicaid Services. Medicaid Drug Rebate Program. January 22, 2021. Accessed August 3, 2021. https://www.medicaid.gov/medicaid/ prescription-drugs/medicaid-drugrebate-program/index.html

9. Center for Evidence-based Policy at Oregon Health \& Science University. Medicaid Preferred Drug List options for states: State Medicaid Alternative Reimbursement and Purchasing Test for High-cost Drugs (SMART-D). February 2020. Accessed August 3, 2021. https:// centerforevidencebasedpolicy.org/ wp-content/uploads/2020/03/ MEDICAID-PREFERRED-DRUG-LISTOPTIONS-FOR-STATES.pdf
10. The Menges Group. Comparison of Medicaid pharmacy costs and usage in carve-in versus carve-out states. America's Health Insurance Program. April 2015. Accessed August 3, 2021. https://www.ahip. org/wp-content/uploads/2015/11/ Medicaid-Pharmacy-Carve-In-FinalPaper-The-Menges-Group-April-2015.pdf

11. The Lewin Group. Projected impacts of adopting a pharmacy carve-in approach within Medicaid capitation programs. Medicaid Health Plans of America. February 2011. Accessed August 3, 2021. https://www.lewin. com/content/dam/Lewin/Resources/ Site_Sections/Publications/ MHPAPaperPharmacyCarve-In.pdf

12. Motheral BR. Pharmaceutical step-therapy interventions: a critical review of the literature. J Manag Care Pharm. 2011;17(2):143-55. doi:10.18553/ jmcp.2011.17.2.143

13. Farley JF, Cline RR, Schommer JC, Hadsall RS, Nyman JA. Retrospective assessment of Medicaid step-therapy prior authorization policy for atypical antipsychotic medications. Clin Ther. 2008;30(8):1524-07.

14. Kaiser Family Foundation. State Medicaid Preferred Drug Lists. Accessed October 12, 2021. https:// www.kff.org/other/state-indicator/ medicaid-preferred-drug-lists /

15. Centers for Medicare \& Medicaid Services. Medicaid Pharmacy Supplemental Rebate Agreements (SRA). December 2020. Accessed August 3, 2021. https://www.medicaid.gov/medicaidchip-program-information/by-topics/ prescription-drugs/downloads/xxxsupplemental-rebates-chart-current-qtr.pdf

16. National Conference of State Legislatures. Pharmaceutical bulk purchasing. March 2, 2020. Updated August 26, 2021. Accessed August 3, 2021. https:// www.ncsl.org/research/health/bulkpurchasing-of-prescription-drugs.aspx

17. Dranove D, Ody C, Starc A. A dose of managed care: controlling drug spending in Medicaid. Am Econ J Appl Econ. 2021;13(1):170-97. doi:10.1257/app.20190165
18. California Department of Health Care Services. 2021-22 Governor's May revision: Department of Health Care Services highlights. May 14, 2021. Accessed October 12, 2021. https://www.dhcs.ca.gov/ Documents/Budget Highlights/DHCSFY-2021-22-MR-Highlights.pdf

19. California Department of Health Care Services. Medi-Cal Rx: transitioning Medi-Cal pharmacy services from managed care to fee-for-service. Frequently asked questions. Accessed October 12, 2021. https://www.dhcs.ca.gov/ provgovpart/pharmacy/Documents/ FAQs-Medi-Cal-Rx-FAQ-V.9-08122021.pdf

20. Hernandez I, Gellad WF. Differences between managed care and fee-forservice Medicaid in the use of generics for high-rebate drugs: the cases of insulin glargine and glatiramer. J Manag Care Spec Pharm. 2020;26(2):154-59. doi:10.18553/jmcp.2020.26.2.154

21. Bai G, Socal M, Sharp M, Pachman E. Medicaid managed care programs' contracts for generic drugs are inefficient. Health Affairs Blog. May 1, 2019. Accessed August 3, 2021. https://www.healthaffairs. org/do/10.1377/hblog20190426.775617/full/

22. Kentucky Cabinet for Health and Family Services. Medicaid pharmacy pricing: opening the black box. February 19, 2019. Accessed August 3, 2021. https:// chfs.ky.gov/agencies/ohda/Documents1/ CHFSMedicaidPharmacyPricing.pdf

23. Motheral BR, Fairman KA. Changes in PBM business practices in 2019: true innovation or more of the same? J Manag Care Spec Pharm. 2020;26(10):1325-33.

24. Ohio Auditor of State. Ohio's Medicaid managed care pharmacy services. Auditor of state report. August 16, 2018. Accessed August 3, 2021. https://ohioauditor.gov/ auditsearch/Reports/2018/Medicaid_ Pharmacy_Services_2018_Franklin.pdf

25. Rutledge v Pharmaceutical Care Management Association, No. 18-540 (US 2020). Accessed February 17, 2021. https://www.supremecourt.gov/ opinions/20pdf/18-540_m640.pdf

26. Salako A, Ullrich F, Mueller KJ. Update: independently owned pharmacy closures in rural America, 2003-2018. Rural Policy Brief No. 2018-2. July 2018. Accessed August 3, 2021. https://rupri. public-health.uiowa.edu/publications/ policybriefs /2018/2018\%20Pharmacy\%20 Closures.pdf 
27. Office of Senator Chuck Grassley. Grassley, Wyden ask HHS watchdog to investigate middlemen 'spread pricing.' April 10, 2019. Accessed August 3, 2021. https://www.grassley.senate.gov/news/news-releases/ grassley-wyden-ask-hhs-watchdog-investigate-middlemen-spread-pricing

28. Louisiana State Legislature. SB239: 2019 Regular Session. Accessed August 3, 2021. http://www.legis.la.gov/legis/ ViewDocument.aspx?d=1144061

29. Small L. More states choose to carve out Medicaid drug benefits. AIS Health. February 3, 2021. Accessed October 12, 2021. https://aishealth.com/ drug-benefits/more-states-choose-tocarve-out-medicaid-drug-benefits /

30. New York Department of Health. Pharmacy carve out. October 2021. Accessed October 12, 2021. https://www. health.ny.gov/health care/medicaid/ redesign/mrt2/pharmacy_carve_out/

31. Rounds KA. Letter to The Honorable Neal M. Kurk, Chairman Fiscal Committee of the General Court and Governor Christopher T. Sununu: Requested Action. New Hampshire Department of Health and Human Services. May 22, 2018. Accessed August 3, 2021. https:// sos.nh.gov/media/cngfk05y/009-gcagenda-062018.pdf

32. Pednekar P, Peterson A. Mapping pharmacy deserts and determining accessibility to community pharmacy services for elderly enrolled in a State Pharmaceutical Assistance Program. PLoS One. 2018;13(6):e0198173.

33. Palmer JD, Pettit CT, McCulla IM. Medicaid managed care financial results for 2018. Milliman. June 2019. Accessed August 3, 2021. https://www.milliman. com/-/media/milliman/importedfiles/ ektron/medicaid managed care financial_results_for_2018.ashx?la $=$ en\&hash $=5$ CA0B07168EA2A6C9AB8C4AEDBB435EE

34. Minnesota Department of Human Services. Outcomes-based purchasing redesign and next generation integrated health partnership (IHP): request for comment (RFC) responses. Accessed August 3, 2021. https://mn.gov/dhs/assets/external-opr-rfc-post tcm1053-323342.pdf
35. Myers and Stauffer. Oregon Health Authority: evaluation of a single or aligned preferred drug list. July 31, 2018. Accessed August 31, 2021. https:// sharprx.net/uploads/3/4/0/5/34054542/ oregon_health_authority_-_evaluation_ of a single or aligned pdl 07.31.2018.pdf

36. Vela L. How physicians can help reduce wasteful drug spending. Commonwealth Fund Blog. September 5, 2019. Accessed August 3, 2021. https://www.commonwealthfund.org/ blog/2019/how-physicians-can-helpreduce-wasteful-drug-spending

37. Swartz K, Farley Short P, Roempke Graefe D, Uberoi N. Reducing Medicaid churning: extending eligibility for twelve months or to end of calendar year is most effective. Health Aff (Millwood). 2015; 34(7):1180-87.

38. Brinkley-Rubinstein L, Macmadu A, Marshall BDL, et al. Risk of fentanylinvolved overdose among those with past year incarceration: findings from a recent outbreak in 2014 and 2015. Drug Alcohol Depend. 2018;185:189-91.

39. Munshi KD, Mager D, Ward KM, Mischel B, Henderson RR. The effect of Florida Medicaid's state-mandated formulary provision on prescription drug use and health plan costs in a Medicaid managed care plan. J Manag Care Spec Pharm. 2018;24(2):124-31. doi:10.18553/ jmcp.2018.24.2.124

40. Texas Medical Association. Testimony by Ryan Van Ramshorst, MD to the Texas Senate Health and Human Services Committee. March 29, 2017. Accessed August 3, 2021. https://www.texmed.org/ Template. aspx id $=44513$

41. Gifford K, Ellis E, Coulter Edwards B, et al. States focus on quality and outcomes amid waiver changes: results from a 50-state Medicaid budget survey for state fiscal years 2018 and 2019. Kaiser Family Foundation. October 25, 2018. Accessed October 12, 2021. https://www.kff.org/medicaid/report/ states-focus-on-quality-and-outcomesamid-waiver-changes-results-from-a50-state-medicaid-budget-survey-forstate-fiscal-years-2018-and-2019/
42. Naci H, Kesselheim AS. Specialty drugs - a distinctly American phenomenon. N Engl J Med. 2020;382:2179-81.

43. Schneiter E. States and prescription drugs: an overview of state programs to rein in costs. National Academy for State Health Policy. April 2016. Accessed August 3, 2021. https://www.nashp.org/wp-content/uploads/2016/04/Drug-Brief1.pdf

44. Auty SG, Shafer PR, Dusetzina SB, Griffith KN. Association of Medicaid managed care drug carve outs with hepatitis c virus prescription use. JAMA Health Forum. 2021;2(8):e212285.

45. Loftus P. States work to strike deals for hep c drug discounts. Wall Street Journal. January 29, 2015. Accessed October 13, 2021. https://www.wsj.com/ articles/states-work-to-strike-deals-forhep-c-drug-discounts-1422492687

46. Sommers BD, Kesselheim AS. Massachusetts' proposed Medicaid reforms - cheaper drugs and better coverage? N Engl J Med. 2018;378(2):109-11.

47. Rand L, Persad G. Are Medicaid closed formularies unethical? AMA J Ethics. 2019;21(8):e654-60.

48. Park E, Noda A. Alternative drug purchasing arrangements do not justify raising the prices Medicaid pays for brand drugs. Health Affairs Blog. April 3, 2020. Accessed August 3, 2021. https:// www.healthaffairs.org/do/10.1377/ hblog20200325.649781/full/

49. Liu H, Mulcahy A. Why states' 'Netflix model' prescription drug arrangements are no silver bullet. Health Affairs Blog. July 1, 2020. Accessed August 3, 2021. https://www.healthaffairs.org/ do/10.1377/hblog20200629.430545/full/

50. Walser BL, Ross-Degnan D, Soumerai $\mathrm{SB}$. Do open formularies increase access to clinically useful drugs? Health Aff (Millwood). 1996;15(3):95-109. 